\title{
A novel fusogenic herpes simplex virus for oncolytic virotherapy of squamous cell carcinoma
}

\author{
Hiroo Takaoka, Gen Takahashi, Fumi Ogawa, Tomoaki Imai, Soichi Iwai and Yoshiaki Yura*
}

\begin{abstract}
Background: R849 is a neurovirulent $\gamma_{1} 34.5$ gene-deficient form of herpes simplex virus type 1 (HSV-1) and has LacZ genes at the deleted sites of the $\gamma_{1} 34.5$ gene. HF is a spontaneously occurring, fusogenic HSV-1 strain. The purpose of this work was to generate a virus that has the syncytial character of HF, while preserving the $\gamma_{1} 34.5$ gene inactivation profile of R849 virus.

Results: Vero cells were infected with R849 and HF simultaneously and two viruses, RH1 and RH2, expressing the LacZ gene and inducing extensive cell fusion were selected. A polymerase chain reaction (PCR)-based analysis suggested that one copy of the $\gamma_{1} 34.5$ gene is lost in $\mathrm{RH} 1$, whereas both copies are lost in $\mathrm{RH} 2$, and that the $\gamma_{1} 34.5$ gene is replaced by a R849-derived DNA fragment with the LacZ gene. These viruses produced larger plaques and more progeny than the parental viruses. Infection with $\mathrm{RH} 2$ decreased the viability of oral squamous cell carcinoma (SCC) cells most strongly. When $\mathrm{RH} 2$ was injected into xenografts of oral SCC in nude mice, multinucleated cells were produced and the growth of the tumors was suppressed significantly.

Conclusion: These results indicate that novel oncolytic HSV-1 vectors can be produced with the genetic background of the oncolytic HSV-1 HF, and that RH2 is deficient in $\gamma_{1} 34.5$ genes and shows extensive cytopathic effects in oral SCC cells. RH2 may be useful in oncolytic virotherapy for oral SCC.
\end{abstract}

Keywords: herpes simplex virus mutant, oncolytic virotherapy, oral squamous cell carcinoma, cell fusion

\section{Background}

Carcinoma of the oral cavity represents $4 \%$ of all malignancies in men and $2 \%$ in women, with the majority of these tumors being squamous cell carcinomas (SCCs) [1]. Despite improvements in both the surgical and pharmacological management of oral malignancies, the 5 -year survival rate for oral cancer is very poor at approximately $53 \%$ mainly because of the advanced state of the disease at the time of presentation [2]. There is no effective treatment for advanced symptoms such as skin metastasis.

Oncolytic virotherapy with herpes simplex virus type 1 (HSV-1) is based on the ability of an attenuated virus to destroy the infected tumor cells [3-5]. Most cancer patients have immunity against $\mathrm{HSV}-1$ and require repeated administration of the $\mathrm{HSV}-1$ vector, so the virus must be delivered locally to prevent its inactivation

\footnotetext{
* Correspondence: yura@dent.osaka-u.ac.jp

Department of Oral and Maxillofacial Surgery, Osaka University Graduate School of Dentistry, Osaka University, Suita, Osaka, Japan
}

by neutralizing antibodies [6-8]. In this aspect, oral cancer has the advantage of accessibility.

A number of HSV-1 vectors have been developed for solid tumors. Most of these have the main neurovirulence gene $\gamma_{1} 34.5$ removed, which severely restricts their ability to replicate in the adult central nervous system and cause a latent infection [9,10]. G207 has two deletions at $\gamma_{1} 34.5$ and ribonucleotide reductase (UL39)[11]. NV1020 expresses one of the two $\gamma_{1} 34.5$ genes allowing the virus to replicate more efficiently without compromising safety $[6,12,13]$. OncoVEX ${ }^{\text {GM-CSF }}$ is deleted of the $\gamma_{1} 34.5$ gene, and ICP47, which otherwise blocks antigen presentation. In addition, a granulocyte macrophage colony-stimulating factor (GM-CSF) gene is inserted to enhance the immune response to tumor antigens released after the virus replicates [7]. Another type of HSV-1 vector developed to improve local antitumor activity has the ability to form a syncytium $[8,14]$. HF10, a clone of HF, is a spontaneously occurring, highly attenuated virus [15-17]. It too can form a large syncytium in a variety of cell types and has strong anti-tumor 
activity. In clinical trials, HF10 was found to be effective against breast cancer, pancreatic cancer, and head and neck cancer [18-20].

We reported that a combination of $\gamma_{1} 34.5$ gene-deficient HSV-1 R849 [21] and HF exerted a greater suppressive effect on xenografts of human oral SCC in nude mice than did repeated injections of R849 [22], indicating the effectiveness of HF as an oncolytic virus. We speculated that recombinant forms of these viruses might be highly fusogenic (as HF) and still lack the neurovirulent $\gamma_{1} 34.5$ gene. To examine this possibility, an attempt was made to select candidate recombinants after infecting permissive cells with R849 and HF simultaneously. An isolate from the cultures, RH2, induced extensive cell fusion in cell cultures and cancer tissue and suppressed tumor growth at a low dose.

\section{Materials and methods Cells and virus}

The human oral SCC cell line SAS was obtained from the Japanese Collection of Research Bioresources (Tokyo, Japan). SAS cells were cultured in Dulbecco's modified Eagle's medium supplemented with $10 \%$ fetal bovine serum, $2 \mathrm{mM}$ L-glutamine, $100 \mathrm{U} / \mathrm{ml}$ penicillin, and 100 $\mu \mathrm{g} / \mathrm{ml}$ streptomycin and grown in an incubator at $37^{\circ} \mathrm{C}$ in a humidified atmosphere with $5 \% \mathrm{CO}_{2}$. For Vero monkey kidney cells, Eagle's minimal essential medium containing $5 \%$ calf serum and $2 \mathrm{mM} \mathrm{L}$-glutamine was used. HSV-1 mutant R849 [22,23] and HF $[15,16]$ were grown in semi-confluent Vero cell monolayers. The infectivity of HSV-1 was determined by plaque formation on Vero cell monolayers covered with $0.3 \%$ methylcellulose.

\section{The 3-(4,5-dimethylthiazol-2-yl)-2,5-diphenyltetrazolium bromide (MTT) assay}

Cells grown in 96-well culture dishes were infected with HSV -1 at a multiplicity of infection (MOI) of 0.01 , while controls were mock- infected. After incubation for various intervals, $10 \mu \mathrm{l}$ of a $5 \mathrm{mg} / \mathrm{ml} \mathrm{MTT}$ solution was added to each well with $100 \mu \mathrm{l}$ of medium. Cells were allowed to incubate for $4 \mathrm{~h}$ at $37^{\circ} \mathrm{C}$, and then $100 \mu \mathrm{l}$ of $0.04 \mathrm{~N} \mathrm{HCl}$ in isopropanol was added. They were mixed thoroughly to dissolve the dark blue crystal. After standing overnight at room temperature, the plates were read on a Benchmark Plus microplate spectrophotometer (Bio-Rad Laboratories, Hercules, CA) with a reference wavelength of $630 \mathrm{~nm}$ and a test wavelength of $570 \mathrm{~nm}$. Background absorbance at $690 \mathrm{~nm}$ was subtracted from the $570 \mathrm{~nm}$ reading. Changes from controls (room air) were calculated.

\section{Polymerase chain reaction (PCR) analysis}

The $\gamma_{1} 34.5$ and lac $Z$ gene sequences were amplified by PCR using specific primers [23]: LacZ forward, 5'-
GCGTTACCCAACTTAATCG -3'; and LacZ reverse, 5' TGTGAGCGAGTAACAACC -3' (PCR product; 320 bp), $\gamma_{1} 34.5$ forward, 5'-TCGTCGGACGCGGACTCGGGAACGGTGGAG-3' $\gamma_{1} 34.5$ reverse, 5'-CTCCACGCCCAACTCGGAACCCGCGGTCAG-3' (PCR product; $132 \mathrm{bp})$

The amplification was carried out in a volume of $50 \mu \mathrm{l}$ for 30 cycles with a denaturing temperature of $94^{\circ} \mathrm{C}$ for $30 \mathrm{sec}$, an annealing temperature of $60^{\circ} \mathrm{C}$ for $30 \mathrm{sec}$, and an extension temperature of $72^{\circ} \mathrm{C}$ for 2 min using a GeneAmp PCR system 9700 (Applied Biosystems, CA, USA). PCR products were subsequently size-fractionated on $2 \%$ agarose gels, stained with $1 \mu \mathrm{g} / \mathrm{ml}$ ethidium bromide and photographed under transmitted UV light.

\section{Digestion of viral DNA and Southern blot analysis}

Viral DNA was isolated after the lysis of infected Vero cells with SDS-proteinase K, repeated phenol-chloroform extraction, following the method of Hirt [24], and ethanol precipitation. For Southern blot analysis, DNA digested by Bam HI endonuclease (NEW ENGLND BioLabs, MA, USA) was separated by agarose gel electrophoresis and transferred to a nylon membrane Hybond$\mathrm{N}+$ (Amersham Biosciences, UK). The PCR product of LacZ was isolated from the gel, subjected to sequencing and used as a probe. Amplified DNA fragment of LacZ was labeled by Gene Images AlkPhos Direct Labeling and Detection System (Amersham Biosciences). After hybridization, bounded probe was detected with CDPStar Detection reagent (Amersham Biosciences).

\section{Animal experiments}

Athymic 5-week-old BALB/c (nu/nu) female mice were obtained from Clea Japan (Tokyo, Japan). Mice were subcutaneously injected with $1 \times 10^{6}$ SAS cells. Once the tumor reached approximately $5 \mathrm{~mm}$ in diameter, animals were divided into 4 groups of 6 animals each. Animals were administered a single intratumor (i.t.) injection of $1 \times 10^{5}$ plaque forming units (PFU) of $\mathrm{R} 849, \mathrm{HF}$, or RH2 suspended in $50 \mu \mathrm{l}$ of phosphate-buffered saline (PBS ). Animals in the control group received $\mathrm{PBS}$ instead of $\mathrm{HSV}-1$. The experiment was started at the time HSV-1 was injected. Bidimensional tumor measurements were performed for 6 weeks with calipers, and tumor volume was determined using the formula for a rotational ellipsoid $\left(\mathrm{L} \times \mathrm{W}^{2} \times 0.5\right)$.

To determine the virus yield in the tumor, an experiment with acute HSV-1 infection was performed. Tumor-bearing mice received an i.t. injection of $1 \times 10^{6}$ PFU of R849, HF, or RH2. The mice were sacrificed at 3,7 , and 14 days after injection of HSV-1 and tumors were removed. They were suspended in two volumes of PBS, homogenized and centrifuged after three rounds of freezing and thawing. The supernatant was harvested 
and the virus titer (PFU/ tumor (g)) was measured by plaque assay using Vero cell monolayers.

Another series of experiment was performed for immunohistochemical staining. HSV-1 was injected in the tumors at a dose of $1 \times 10^{6}$ PFUs and the tumors were removed at 3 and 7 days after injection. Tumors that received PBS were used for the control. Experiments were performed with the approval of the Institute of Laboratory Animals, Osaka University Graduate School of Dentistry.

\section{Histopathological examination and 5-bromo-4-chloro-3- indolyl- $\beta$-D- galactopyranoside (X-gal) staining}

For X-gal staining, R849- infected cells were placed in a fixative containing $0.2 \%$ glutaraldehyde and $2 \%$ formaldehyde in PBS for $1 \mathrm{~h}$, and submerged in cold PBS. Cells were then left overnight in a substrate solution containing $1 \mathrm{mg} / \mathrm{ml} \mathrm{X-gal} \mathrm{(Sigma),} 5 \mathrm{mM}$ potassium ferricyanide, $5 \mathrm{mM}$ potassium ferrocyanide, and $2 \mathrm{mM}$ magnesium chloride in PBS and washed with PBS.

Tumors were removed, placed in 10\% buffered formalin for fixation, and embedded in paraffin wax. Sections were stained with hematoxylin and eosin (H-E). For immunohistochemical staining, endogenous peroxidase was blocked by incubation in $3 \% \mathrm{H}_{2} \mathrm{O}_{2}$ in water for 5 $\mathrm{min}$ at room temperature. Sections were washed in PBS and then incubated with rabbit polyclonal antibody against HSV-1 (diluted 1:500, DAKO, Glostrup, Denmark) for $30 \mathrm{~min}$ at room temperature. After another wash, slides were reacted with Envision+System-HRP Labelled Polymer Anti Rabbit (DAKO) for $30 \mathrm{~min}$ at room temperature. HSV-1 antigen was visualized by treating with diaminobenzidine (DAB) (DAKO, Glostrup, Denmark), counterstained with hematoxylin, and mounted with Entellan (Merck, Darmstadt, Germany). Computer-assisted analysis of immunohistochemical staining was performed using WinROOF image-processing software (Mitani Corp., Tokyo, Japan). This software allowed accurate identification and calculation of the immunostained area [25]. The size $\left(\mu \mathrm{m}^{2}\right)$ of HSV-1 antigen-positive multinucleated cells was calculated after examining signals in 3 to 5 sections, using high-power ( $\times 40$ objective and $\times 10$ ocular) magnification. At least 3 samples were measured and mean values \pm standard deviation (SD) were determined.

\section{Statistical analysis}

An SPSS for Windows computer program (SPSS Inc., Chicago, IL, USA) was used for statistical analyses. Results are reported as means \pm SD. Comparison of mean cell viability, plaque size and virus yield in tumors were achieved using one-way ANOVA, followed by Tukey's honestly significant differences (HSD) test. Mean size of HSV-1 antigen-positive multinucleated cells was compared using the unpaired $t$-test. For the repeated measures part of the analyses of tumor volumes, general linear model (GLM) procedure was used to conduct a repeated measures design analyzed. When overall analyses determined significance, Tukey's HSD test was used to examine pairwise differences. P values of less than 0.05 were considered statistically significant.

\section{Results}

\section{Production of recombinant viruses in Vero cells}

HSV-1 R849 has a LacZ gene inserted at the deleted site of the $\gamma_{1} 34.5$ gene [21]. R849-infected cells became rounded and showed X-gal staining, indicating the expression of LacZ. The BamHI profiles of HF10 showed a loss of the $\mathrm{B}$ and $\mathrm{E}$ fragments and the genome has a deletion of $3832 \mathrm{bp}$ to the right of the UL and UL/IRL junction [17]. Cell-fusion appeared in the cells infected with HF as well as HF10 [22,26]. Schema of the genomic structure of these viruses are shown in Figure 1. In this study, an attempt to generate a virus that has the syncytial character of HF, while preserving the $\gamma_{1} 34.5$ gene inactivation profile of R849 virus by recombination in cell culture was made. For recombination, Vero cells were infected with R849 and HF simultaneously, at different MOIs. The MOI was 0.01 for R849 and changed from 0.001 to 0.1 for HF. When the MOI of HF was 0.02 or 0.03 , several syncytia with X-gal staining were observed and syncytia were pick up under a phase contrast microscope. Viruses recovered from the syncytia were diluted and underwent plaque formation in Vero cells. This cloning procedure was repeated at least five times and two virus clones showing extensive cell fusion, RH1 and RH2, were used for further study. When human oral SCC SAS cells were infected with R849, and cultured for $24 \mathrm{~h}$, rounded cells were positive for X-gal staining. Large syncytia were positive for X-gal staining in RH2-infected cells (Figure 2).

\section{PCR analysis of RH1 and RH2}

To determine the presence of the LacZ gene inserted into the deleted site of the $\gamma_{1} 34.5$ gene of R849, the PCR was performed. A LacZ-specific band of 320 bp was detected in R849, RH1 and RH2, but not in HF. When DNA extracted from HSV-1-infected cells was subjected to a Southern blot analysis using the LacZ gene as a probe, a LacZ-specific band was detected in R849, RH1 and RH2; the density in R849 and RH2 was similar, but that in RH1 was reduced by approximately half (Figure 3 ). In the PCR analysis for the $\gamma_{1} 34.5$ gene, a specific 132-bp band was detected in HF and RH1, but not in R849 and RH2 (Figure 3).

\section{Formation of plaques by $\mathrm{RH} 1$ and $\mathrm{RH} 2$ in SAS cells}

The fusogenic ability of HSV-1 strains was examined by plaque-forming assays in oral SCC cells. SAS infected 


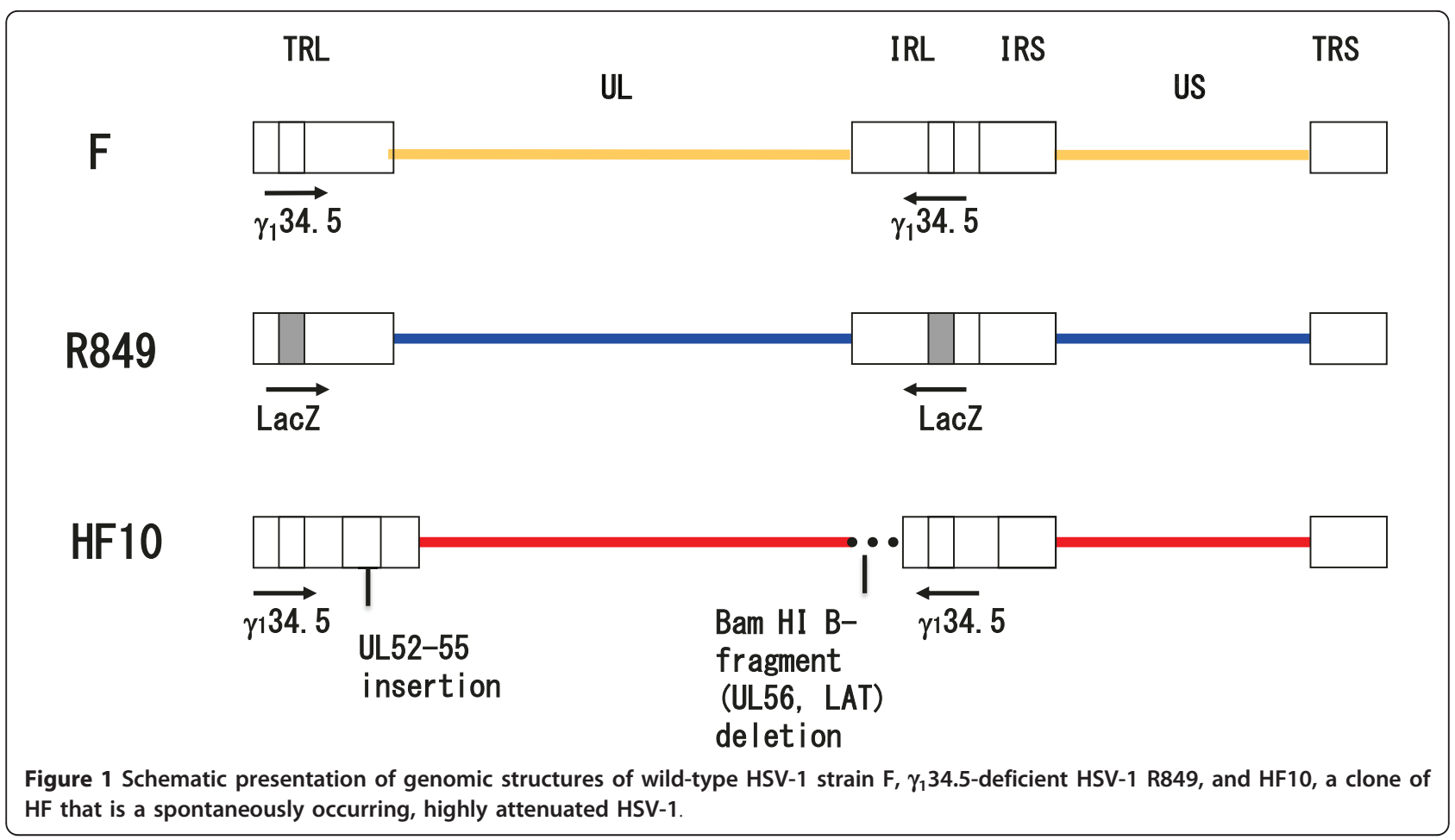

with R849, HF, RH1 and RH2 were incubated for $48 \mathrm{~h}$, and the cytopathic effect was observed. In the cells infected with RH1 and RH2, extensive cell fusion was observed (Figure 4A). Mean plaque size was greater in RH1 and RH2 than that in HF (RH2 > RH1 > HF); a 2fold increase was observed in $\mathrm{RH} 2$ as compared with HF (Figure 4B). There was a significant $(\mathrm{P}<0.05)$ difference among virus strains.

\section{Production of RH1 and RH2 in SAS cells}

The ability of oral SCC cells to support the replication of HSV-1 strains was examined. SAS cells were infected with R849, HF, RH1 or RH2 at a MOI of 0.01 and the virus production was determined at 48, 72, and $96 \mathrm{~h}$ after infection. $\mathrm{RH} 1$ and $\mathrm{RH} 2$ produced more infectious virus than the parental viruses. At $96 \mathrm{~h}$ after infection, as compared with the yield of HF, there were 4.2-fold
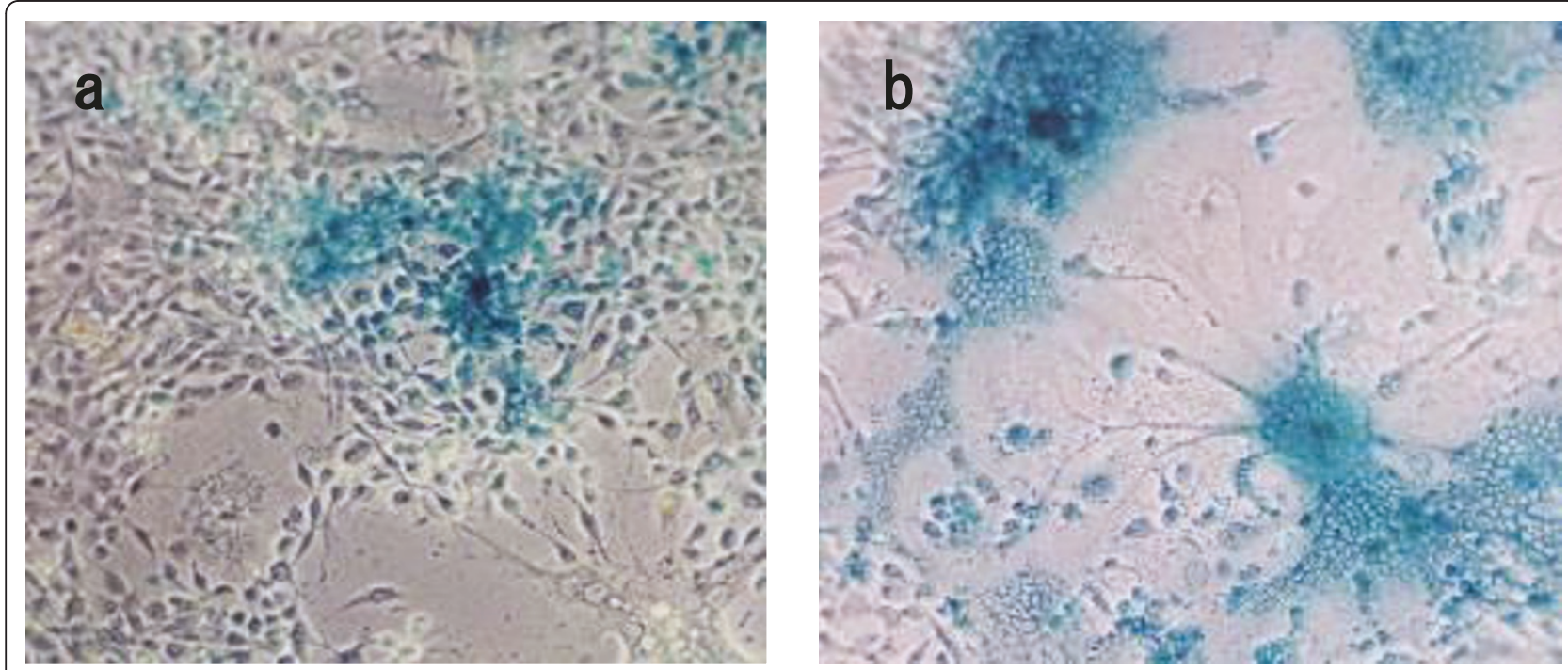

Figure 2 Cytopathic effect of R849 (a) or RH2 (b) in human oral SCC cells. SAS cells were infected with HSV-1 at an MOI of 0.01 and cultured at $37^{\circ} \mathrm{C}$ for $24 \mathrm{~h}$. The infected cells were fixed and subjected to X-gal staining. 

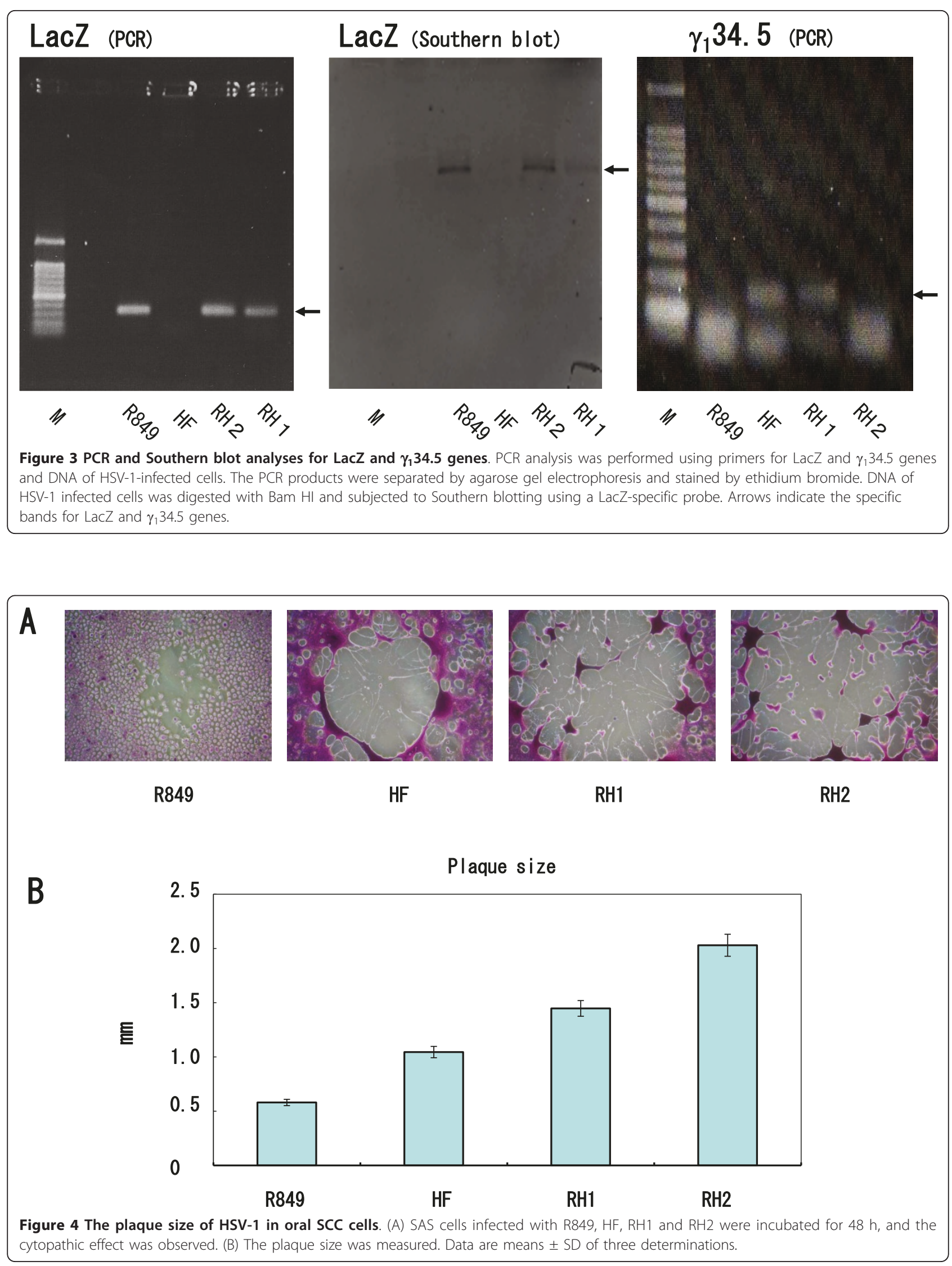
and 23.8-fold increases in those infected with $\mathrm{RH} 1$ and RH2 (Figure 5).

\section{Suppression of the viability of oral SCC cells by $\mathrm{RH}$ and $\mathrm{RH} 2$}

The MTT assay measures the activity of mitochondria. When SAS cells infected with R849, HF, RH1 or RH2 at an MOI of 0.01 were cultured for $96 \mathrm{~h}$, the values were decreased to $88,54,64$ and $38 \%$ of the untreated control, respectively (Figure 6). There was a significant $(\mathrm{P}<$ 0.05) difference between HF and RH2.

\section{Histopathology of HSV-1-injected tumors}

To examine the expression of HSV-1 antigens, tumors were injected with R849, HF, or RH2 at a dose of $1 \times$ $10^{6} \mathrm{PFU}$ and subjected to immunohistochemical staining. Three days after injection, the histological change caused by R849 was cell rounding and HSV-1 antigens appeared in these cells. Multinucleated cells appeared in the tumors that received HF or RH2. Especially, both HSV-1 antigen-positive and- negative multinucleated giant cells were observed in $\mathrm{RH} 2$-injected tumors (Figure 7). Seven days after the injection of HSV-1, necrotic parts surrounded by HSV-1 antigenpositive cells spread in the tumors. Most multinucleated cells became positive for HSV-1 staining in $\mathrm{RH} 2$-injected tumor (Figure 8). When measured at 14 days, the mean size of multinucleated cells induced by
$\mathrm{RH} 2$ was significantly greater than that induced by HF $(\mathrm{P}<0.05)$ (Figure 9).

\section{Viruss yields in oral SCC xenografts in nude mice}

To examine the replication of HSV-1 in vivo, SAS xenografts in nude mice were given $1 \times 10^{6} \mathrm{PFU}$ of R849, $\mathrm{HF}$, or RH2 and virus production in the tumors was examined at 3, 7 and 14 days after injection. The viral titer declined 7 days after injection, but a slight increase was observed 14 days in all strains; the titers in R849, $\mathrm{HF}$ and RH2 were $3 \times 10^{3}, 2 \times 10^{4}$ and $3 \times 10^{4} \mathrm{PFU} /$ tumor (g), respectively. There was no significant difference among the strains (Figure 10). The RH2 harvested from tumor tissues at 14 days also showed extensive cell fusion in SAS cells.

\section{Suppressive effect of HSV-1 infection on the growth of oral SCC xenografts in nude mice}

Nude mouse tumors were injected subcutaneously with R849, HF, or RH2 at a dose of $1 \times 10^{5}$ PFU. Control animals were given PBS. In the control group, tumors grew rapidly and the tumor volume at 35 days was 3300 $\mathrm{mm}^{3}$ (Figure 11), whereas the tumor growth of HSV-1treated animals was suppressed and the tumor volumes were less than $2300 \mathrm{~mm}^{3}$. When tumor volume was compared at day 35 , a significant difference between the control and HF group or RH2 group $(\mathrm{P}<0.05)$ was found. No symptoms of neurological abnormality and

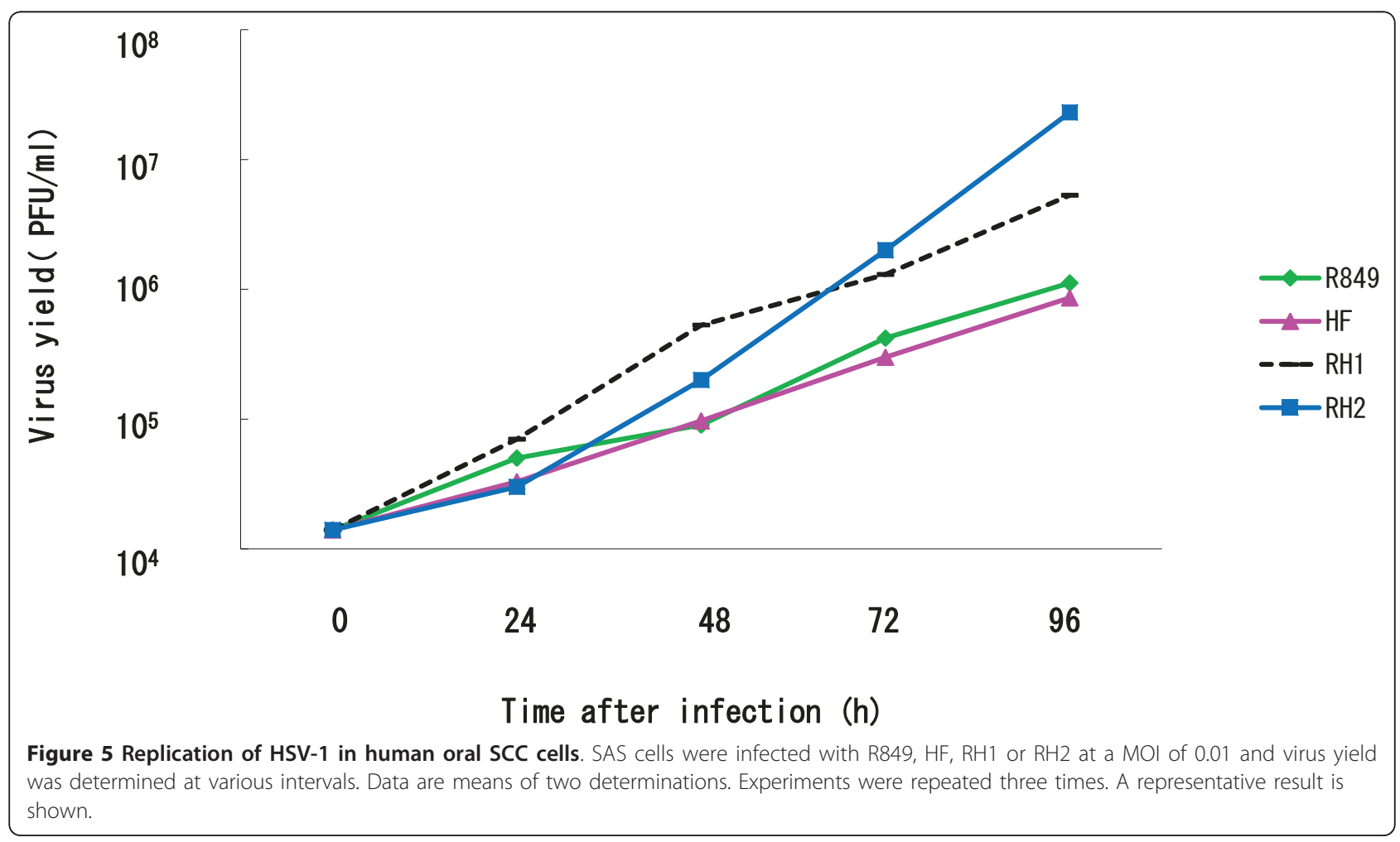




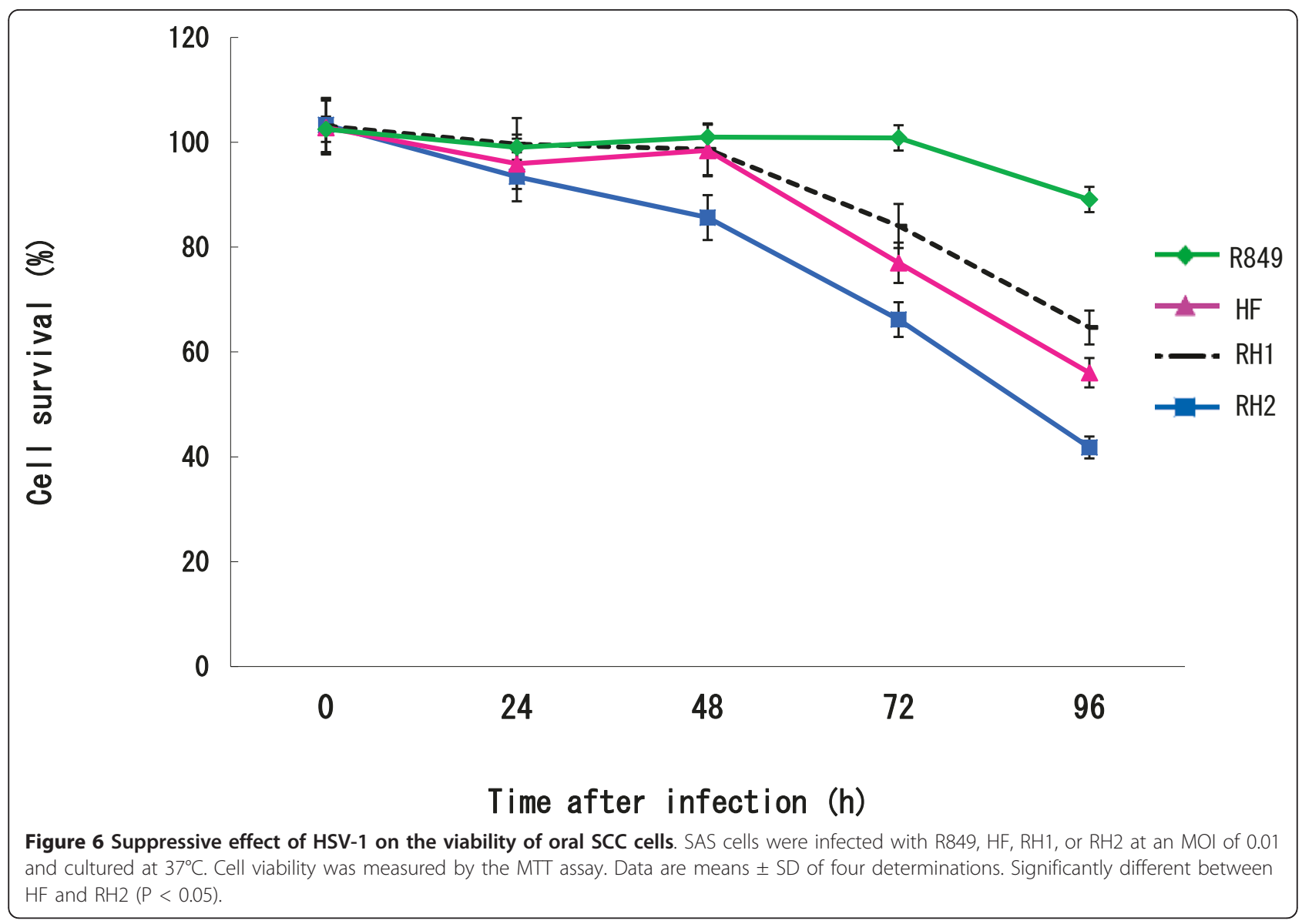

skin reaction at the injected sites were observed during the experiment.

\section{Discussion}

Several viruses that kill their target cells through syncytial formation have been described. The HSV-1 vector Synco-2D has gibbon ape leukemia virus fusogenic membrane protein (GALV-FMG) to causes syncytia to spread in the tumor by cell fusion [14]. Israyelyan et al. [8] reported a syncytial mutation in the gB (Arg to His change at aa 858) and gK (Ala to Val change at aa 40) genes to enhance the fusogenicity of OncdSyn. In this context, a fusogenic HSV-1 under clinical study is HF10. The genome of HF10 has extensive rearrangements at both ends of the UL region and lacks the expression of UL56 and LATs [26]. The lack of UL56 reduces the neuroinvasiveness of $\mathrm{HSV}$ without affecting viral replication in vitro. Diakidi-Kosta et al. [27] reported that marker transfer experiments and DNA sequence analysis mapped the syncytial phenotype to a T-C base substitution at codon 787 of the cytoplasmic domain of mature gB, that resulted in Leu to Pro substitution and consequently belonged to the syncytial locus. Indeed, HF10 has an amino acid substitution (Leu to
Pro at aa 787) in glycoprotein B (gB) [26], suggesting that the syncytial phenotype of HF10 is ascribed to this amino acid change. HF from which HF10 was cloned has the characteristics of an oncolytic virus. To construct a novel virus that is less neurovirulent with the genetic background of HF, Vero cells were infected with R849 and HF at different MOIs. Since R849 has the LacZ gene inserted into the deleted $\gamma_{1} 34.5$ gene, the expression of LacZ is a marker of a R849-specific structure. We selected fusogenic viruses with the LacZ gene, and obtained RH1 and RH2. When they were subjected to PCR and Southern blot analysis, RH1 and RH2 revealed the presence of the LacZ gene, but the density of the gene was lower in RH1 than in R849 and RH2. Consistent with this finding, the $\gamma_{1} 34.5$ gene was detected in RH1, but not RH2. Thus, it is concluded that one copy of the $\gamma_{1} 34.5$ gene is lost in RH1, whereas both copies are lost in RH2, and that the $\gamma_{1} 34.5$ gene is replaced by a $\mathrm{R} 849$-derived DNA fragment with the LacZ gene.

The mean plaque sizes of RH1 and RH2 were significantly greater than that of HF, indicating the ability to induce extensive cell fusion in oral SCC cells. During the simultaneous infection with R849 and HF, a variety 


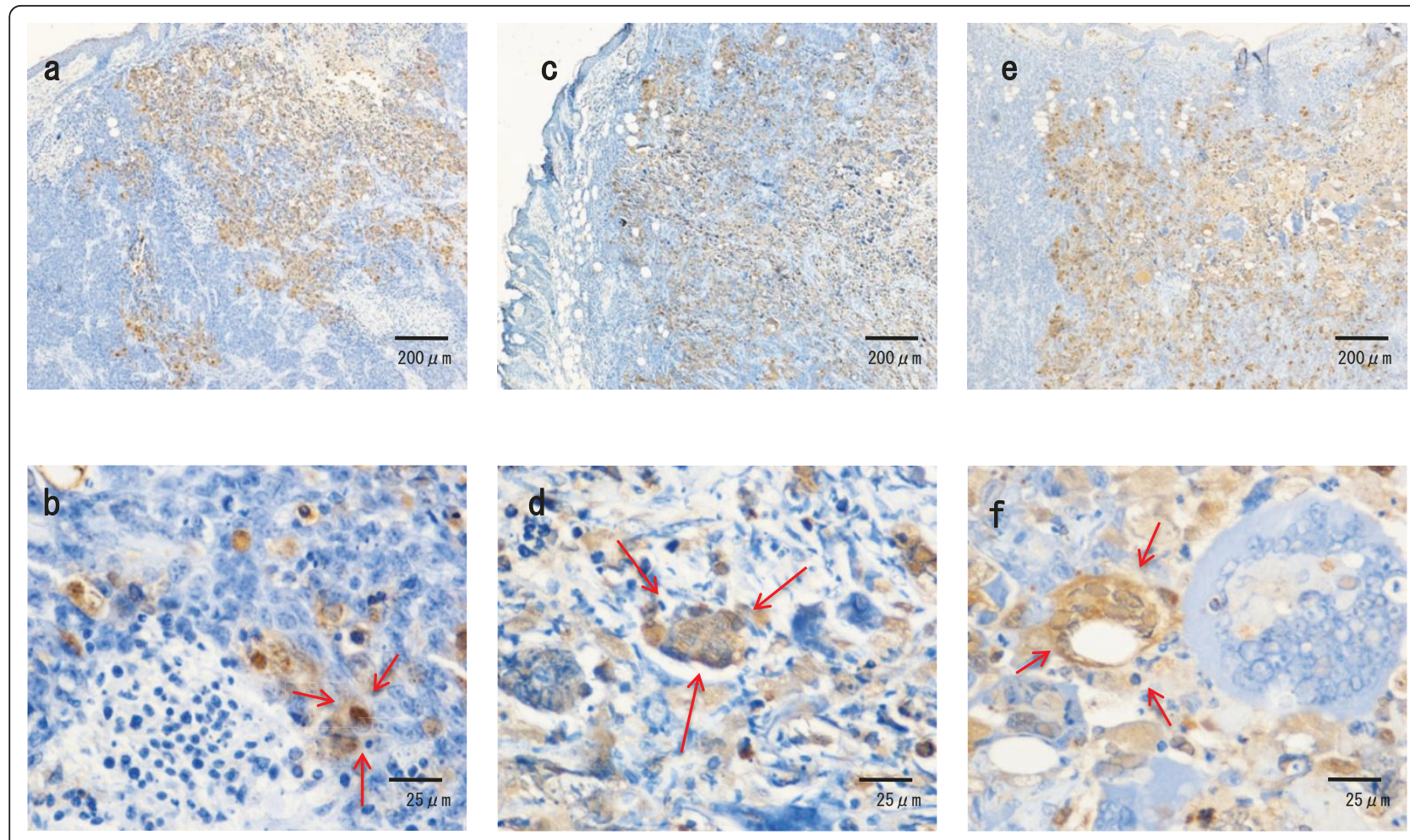

Figure 7 Histopathological changes and virus gene expression in oral SCC xenografts in nude mice. Oral SCC xenografts in nude mice were given $1 \times 10^{6}$ PFUs of R849 $(a, b)$, HF (c, d), or RH2 (e, f). Tumors with skin were removed 3 days after infection and subjected to immunohistochemical staining using antibody against HSV-1. Arrows indicate rounded cells (b) and multinucleated cells (d, f).

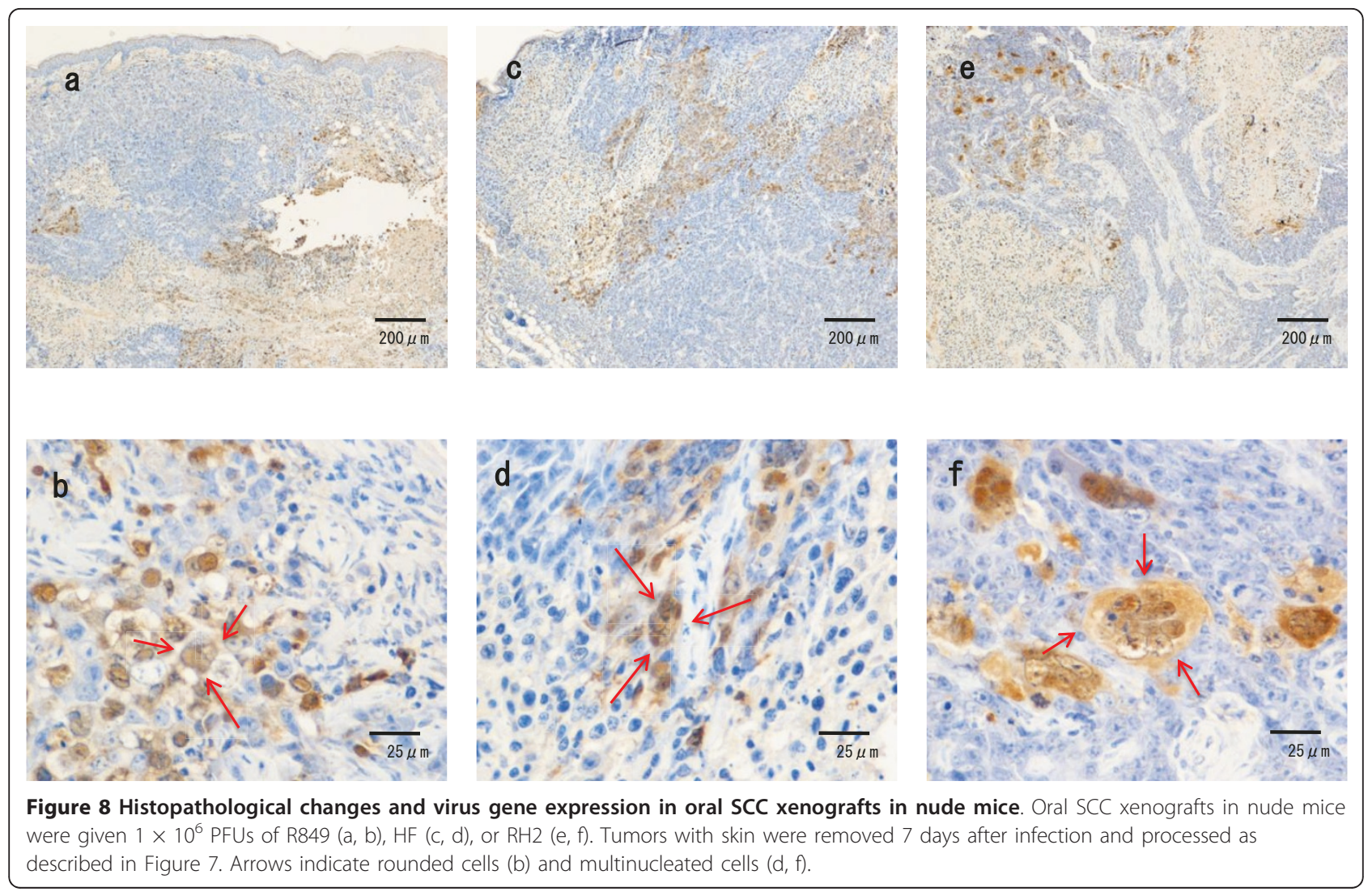



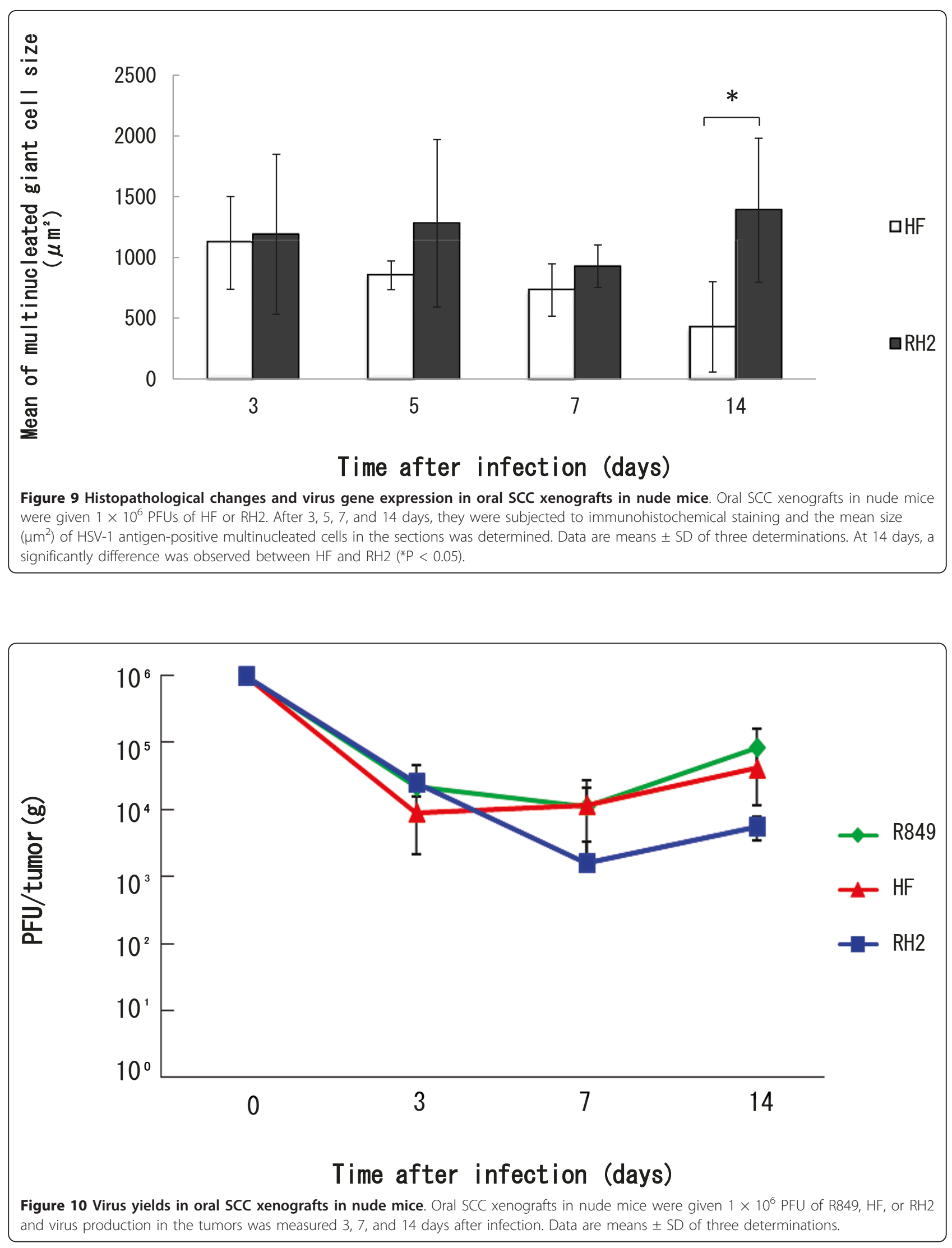


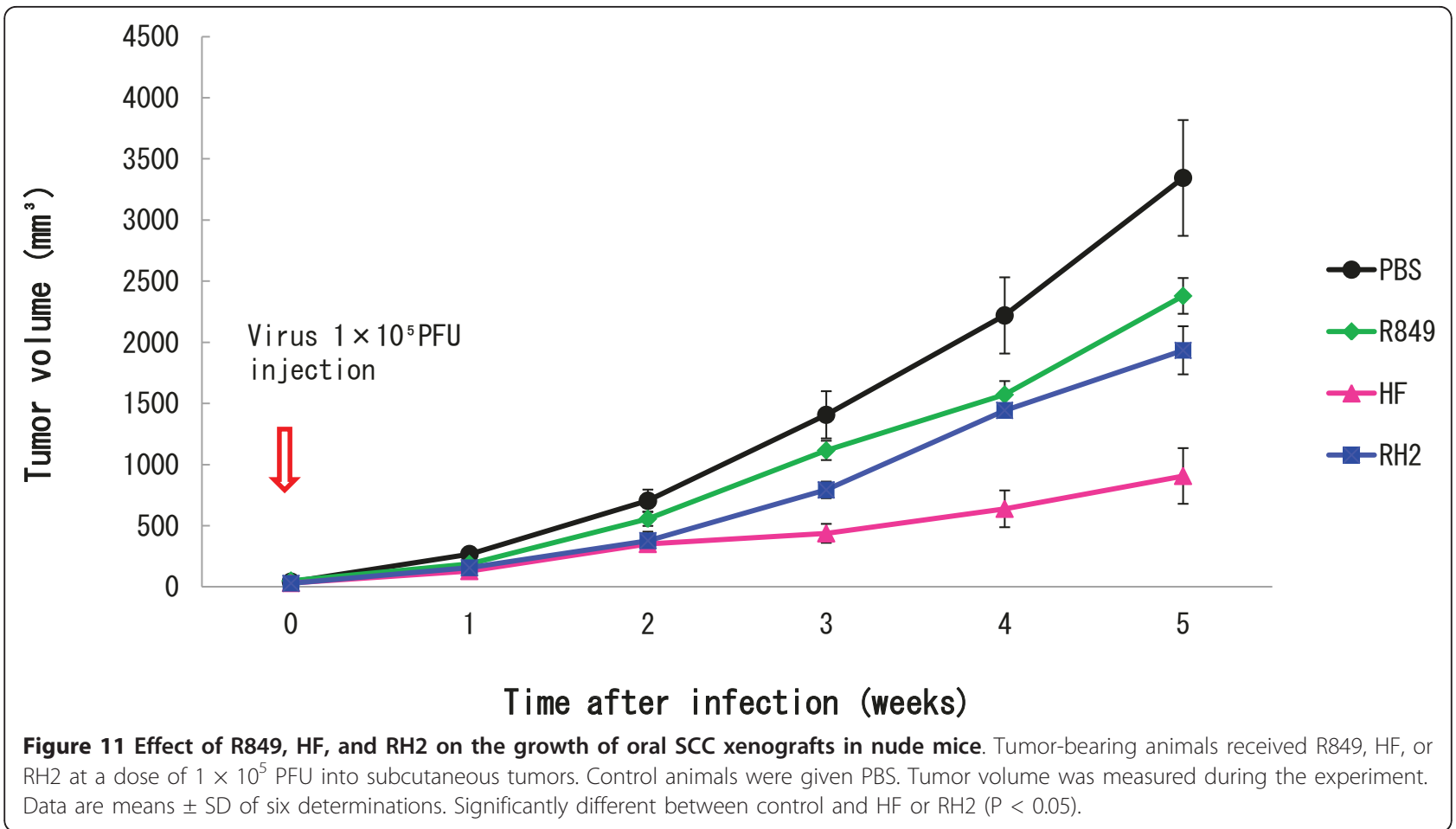

of recombinants with a unique phenotype with or without the $\gamma_{1} 34.5$ gene would be produced, although R849 induces cell rounding. Novel mutations in viral glycoprotein genes responsible for extensive cell fusion might occur during or after recombination. It was reported that OncdSyn with mutations at gB and gK caused extensive virus-induced cell fusion in cell cultures, but the titer in tumor cells was a half log lower than that of the wild-type HSV-1 strain F [8]. Synco-2D with GALVFMG has a significantly increased tumor cell killing ability, but the titer of Synco-2D was also substantially lower than that of the wild-type HSV strain 17 [14]. In the present study, we found that the virus production of RH1 and RH2 was greater than that of the parental viruses. In the MTT assay, RH2 decreased the cell viability most strongly, and RH1 did not exceed the suppressive effect of HF on the growth of tumor cells. Thus, the virus yield in cell culture is not correlated with the ability to induce syncytia and cell death. It can be stated that RH2 has acquired the capability to induce cell fusion and produce virus progeny in oral SCC cells.

Although a number of fusogenic HSV-1 were investigated for their antitumor effect on tumor tissues, the histological alteration associated with HSV-1 infection was not clearly described $[8,14,19]$. In the present study, R849 induced cell rounding in tumors as in cell culture and viral antigen was demonstrated in rounded cells only. On the other hand, infection with $\mathrm{HF}$ or $\mathrm{RH} 2$ induced the formation of multinucleated cells. There was variety in size, but RH2 produced larger multinucleated cells than HF, indicating the phenotype in cell culture to be preserved in tumor tissues. We also found multinucleated cells showing only faint staining 3 days after infection with $\mathrm{RH} 2$. The viral antigen may be diluted in multinucleated cells, because the infection by RH2 progresses rapidly and involves surrounding uninfected cells. The size of HF-induced multinucleated cells decreased during the observation period, whereas no such alteration was observed in RH2 (Figure 9). This represents the difference in the phenotype of these viruses.

To compare the antitumor ability, we injected R849, HF or RH2 into nude mouse tumors at a low dose. Tumors in control animals increased continuously for 5 weeks, while tumor growth was suppressed by the intratumor injection of HSV-1. A significant difference was demonstrated when HF or RH2 was injected, suggesting that RH2 has antitumor activity like HF. However, the antitumor effect of RH2 was slightly blunted. The virus yields in tumors declined gradually, and a slight increase was observed in 14 days, irrespective of the virus used. Thus, these HSV-1s can replicate in the tumors for at least 14 days. It has been shown that the replication of $\gamma_{1} 34.5$ gene-deficient HSV-1 is dependent on the mitogen-activated protein kinase kinase (MEK) activity and/ or phosphoinositide 3-kinase (PI 3-kinase) of the tumor cells [28-30]. This causes the selective replication of the HSV-1 vector including RH2 in tumors. In this respect, 
HF still retained the $\gamma_{1} 34.5$ gene, so that it can grow in tissues irrespective of MEK and PI 3-kinase activities in the tumor cells. This would explain the difference between $\mathrm{HF}$ and $\mathrm{RH} 2$ in the antitumor effect and virus yield. It should be also stated that the phenotype of $\mathrm{RH} 2$, being favorable for oncolytic virotherapy, was stably maintained after passages in oral SCC cells in culture and nude mouse tumors. We found neither general side-effects nor any neurological disorders in the mice, indicating the low neurovirulence of $\mathrm{RH} 2$.

It has been shown that syncytial formation induced by GALV-FMG of Synco-2D can potentiate antitumor immune responses through the increased release of vesicles resembling exosomes [14]. Such structures contain abundant tumor antigens and other molecules involved in antigen presentation (e.g., MHC class I and class II molecules) and can efficiently load dendric cells for cross presentation of tumor antigens [31]. In this regard, intratumoral inoculation of HF10 into mouse cutaneous melanoma inhibited the growth of tumors at both injected and uninjected sites, suggesting the induction of a systemic antitumor immune response by this fusogenic HSV-1 [32]. Thus, RH2 may also enhance tumor antigen presentation by syncytial formation. HF10 is under clinical trials and the genetic structure was published [18-20,26]. It is apparent that the precise structure of the $\mathrm{RH} 2$ genome must be determined prior to clinical study.

\section{Conclusion}

This work was conducted to generate a virus that has the syncytial character of HF, while preserving the $\gamma_{1} 34.5$ gene inactivation profile of $\mathrm{R} 849$ virus. $\mathrm{RH} 2$, a recombinant form of $\mathrm{R} 849$ and $\mathrm{HF}$, had a deletion of the $\gamma_{1} 34.5$ gene and exerted a potent cell killing effect on oral SCC cells through a highly fusogenic ability. RH2 may be a candidate for an HF10-based virus vector suitable for brain tumors as well as oral cancer, because of its defect in the neurovirulent $\gamma_{1} 34.5$ gene.

\section{Acknowledgements \\ This investigation was supported in part by a Grant-in-aid for Scientific Research from the Ministry of Education, Science and Culture of Japan.}

\section{Authors' contributions}

HT performed half of the experiments, GT performed the rest of the experiments, FO succeeded in the isolation of the recombinants viruses, TI participated in drafting the manuscript, SI participated in the pathological analysis and interpretation of the data, and YY was responsible for the project and for the preparation of the manuscript.

The authors read and approved the manuscript.

\section{Competing interests}

The authors declare that they have no competing interests.

Received: 15 March 2011 Accepted: 10 June 2011

Published: 10 June 2011
References

1. Cunningham MJ, Johnson JT, Myers EN, Schramm VL Jr, Thearle PB: Cervical lymph node metastasis after local excision of early squamous cell carcinoma of the oral cavity. Am J Surg 1986, 152:361-366.

2. Jemal A, Siegel R, Ward E, Hao Y, Xu J, Thun MJ: Cancer statistics, 2009. CA Cancer J Clin 2009, 59:225-249.

3. Carew JF, Kooby DA, Halterman MW, Federoff HJ, Fong Y: Selective infection and cytolysis of human head and neck squamous cell carcinoma with sparing of normal mucosa by cytotoxic herpes simplex virus type 1 (G207). Hum Gene Ther 1999, 10:1599-1606.

4. Rowan K: Oncolytic viruses move forward in clinical trials. J Natl Cancer Inst 2010, 102:590-595.

5. Wong HH, Lemoine NR, Wang Y: Oncolytic Viruses for Cancer Therapy: Overcoming the Obstacles. Viruses 2010, 2:78-106.

6. Wong RJ, Kim SH, Joe JK, Shah JP, Johnson PA, Fong Y: Effective treatment of head and neck squamous cell carcinoma by oncolytic herpes simplex virus. J Am Coll Surg 2001, 193:12-21.

7. Liu BL, Robinson M, Han ZQ, Branston RH, English C, Reay P, McGrath $Y$, Thomas SK, Thornton M, Bullock P, Love CA, Coffin RS: ICP34.5 deleted herpes simplex virus with enhanced oncolytic, immune stimulating, and anti-tumour properties. Gene Ther 2003, 10:292-303.

8. Israyelyan A, Chouljenko VN, Baghian A, David AT, Kearney MT, Kousoulas KG: Herpes simplex virus type-1(HSV-1) oncolytic and highly fusogenic mutants carrying the NV1020 genomic deletion effectively inhibit primary and metastatic tumors in mice. Virol J 2008, 5:68.

9. Chou J, Kern ER, Whitley RJ, Roizman B: Mapping of herpes simplex virus1 neurovirulence to $\gamma_{1} 34.5$, gene nonessential for growth in culture. Science 1990, 250:1262-1266.

10. He B, Gross M, Roizman B: The gamma(1) 34.5 protein of herpes simplex virus 1 complexes with protein phosphatase 1 alpha to dephosphorylate the alpha subunit of the eukaryotic translation initiation factor 2 and preclude the shutoff of protein synthesis by double-stranded RNAactivated protein kinase. Proc Natl Acad Sci USA 1997, 94:843-848.

11. Mineta T, Rabkin SD, Yazaki T, Hunter WD, Martuza RL: Attenuated multimutated herpes simplex virus-1 for the treatment of malignant glioma. Nature Med 1995, 1:938-943.

12. Advani SJ, Chung SM, Yan SY, Gillespie GY, Markert JM, Whitley RJ, Roizman B, Weichselbaum RR: Replication-competent, nonneuroinvasive genetically engineered herpes virus is highly effective in the treatment of therapy-resistant experimental human tumors. Cancer Res 1999, 59:2055-2058.

13. Kemeny N, Brown K, Covey A, Kim T, Bhargava A, Brody L, Guilfoyle B, Haag NP, Karrasch M, Glasschroeder B, Knoll A, Getrajdman G, Kowal K, Jarnagin WR, Fong Y: Phase I, open-label, dose-escalating study of a genetically engineered herpes simplex virus, NV1020, in subjects with metastatic colorectal carcinoma to the liver. Hum Gene Ther 2006, 17:1214-1224.

14. Nakamori M, Fu X, Meng F, Jin A, Tao L, Bast RC Jr, Zhang X: Effective therapy of metastatic ovarian cancer with an oncolytic herpes simplex virus incorporating two membrane fusion mechanisms. Clin Cancer Res 2003, 9:2727-2733.

15. Wheeler CE: The effect of temperature upon the production of herpes simplex virus in tissue culture. J Immunol 1958, 81:98-106.

16. Yura Y, Kusaka J, Bando T, Yamamoto S, Yoshida H, Sato M: Enhancement of herpes simplex virus-induced polykaryocyte formation by 12-0tetradecanoyl phorbol 13-acetate: Association with the reorganization of actin filaments and cell motility. Intervirology 2000, 43:129-138.

17. Takakuwa H, Goshima F, Nozawa N, Yoshikawa T, Kimata H, Nakao A, Nawa A, Kurata T, Sata T, Nishiyama Y: Oncolytic viral therapy using a spontaneously generated herpes simplex virus type 1 variant for disseminated peritoneal tumor in immunocompetent mice. Arch Virol 2003, 148:813-825.

18. Nakao A, Kimata H, Imai T, Kikumori T, Teshigahara O, Nagasaka T, Goshima F, Nishiyma Y: Intratumoral injection of herpes simplex virus HF10 in recurrent breast cancer. Ann Oncol 2004, 15:988-989.

19. Fujimoto Y, Mizuno T, Sugiura S, Goshima F, Kohno S, Nakashima T, Nishiyama $Y$ : Intratumoral injection of herpes simplex virus HF10 in recurrent head and neck squamous cell carcinomas. Acta Otolaryngol 2006, 126:1115-1117.

20. Nakao A, Kasuya H, Sahin TT, Nomura N, Kanzaki A, Misawa M, Shirota T, Yamada S, Fujii T, Sugimoto H, Shikano T, Nomoto S, Takeda S, Kodera Y, 
Nishiyama Y: A phase I dose-escalation clinical trial of intraoperative direct intratumoral injection of HF10 oncolytic virus in non-resectable patients with advanced pancreatic cancer. Cancer Gene Ther 2011, 18:167-175.

21. Andreansky S, Soroceanu L, Flotte ER, Chou J, Markert JM, Gillespie GY, Roizman B, Whitley RJ: Evaluation of genetically engineered herpes simplex viruses as oncolytic agents for human malignant brain tumors. Cancer Res 1997, 57:1502-1509.

22. Ogawa F, Takaoka H, Iwai S, Aota K, Yura Y: Combined oncolytic virotherapy with herpes simplex virus for oral squamous cell carcinoma. Anticancer Res 2008, 28:3637-3645.

23. Naito S, Obayashi S, Sumi T, Iwai S, Nakazawa M, Ikuta K, Yura Y: Enhancement of antitumor activity of herpes simplex virus $\gamma_{1} 34.5-$ deficient mutant for oral squamous cell carcinoma cells by hexamethylene bisacetamide. Cancer Gene Ther 2006, 13:780-791.

24. Hirt B: Selective extraction of polyoma DNA from infected mouse cell cultures. J Mol Biol 1967, 26:365-369.

25. Hayashi T, Morishita E, Ohtake H, Oda Y, Ohta K, Arahata M, Kadohira Y, Maekawa M, Ontachi Y, Yamazaki M, Asakura H, Takami A, Nakao S: Expression of annexin II in human atherosclerotic abdominal aortic aneurysms. Thromb Res 2008, 123:274-280.

26. Ushijima Y, Luo C, Goshima F, Yamauchi Y, Kimura H, Nishiyama Y: Determination and analysis of the DNA sequence of highly attenuated herpes simplex virus type 1 mutant HF10, a potential oncolytic virus. Microbes Infect 2007, 9:142-149.

27. Diakidi-Kosta A, Michailidou G, Kontogounis G, Sivropoulou A, Arsenakis M: A single amino acid substitution in the cytoplasmic tail of the glycoprotein B of herpes simplex virus 1 affects both syncytium formation and binding to intracellular heparan sulfate. Virus Res 2003, 93:99-108.

28. Smith KD, Mezhir JJ, Bickenbach K, Veerapong J, Charron J, Posner MC, Roizman B, Weichselbaum RR: Activated MEK suppresses activation of PKR and enables efficient replication and in vivo oncolysis by Deltagamma(1)34.5 mutants of herpes simplex virus 1. J Virol 2006, 80:1110-1120.

29. Sarinella F, Calistri A, Sette P, Palù G, Parolin C: Oncolysis of pancreatic tumour cells by a gamma34.5-deleted HSV-1 does not rely upon Rasactivation, but on the PI 3-kinase pathway. Gene Ther 2006, 13:1080-1087.

30. Pan W, Bodempudi V, Esfandyari T, Farassati F: Utilizing ras signaling pathway to direct selective replication of herpes simplex virus-1. PLoS One 2009, 4:e6514.

31. Bateman AR, Harrington K, Kottke T, Ahmed A, Melcher AA, Gough MJ, Linardakis E, Riddle D, Dietz A, Lohse CM, Strome S, Peterson T, Simari R Vile RG: Viral fusogenic membrane glycoproteins kill solid tumor cells by nonapoptotic mechanisms that promote cross presentation of tumor antigens by dendritic cells. Cancer Res 2002, 62:6566-6578.

32. Watanabe D, Goshima F, Mori I, Tamada Y, Matsumoto Y, Nishiyama Y: Oncolytic virotherapy for malignant melanoma with herpes simplex virus type 1 mutant HF10. J Dermatol Sci 2008, 50:185-196.

doi:10.1186/1743-422X-8-294

Cite this article as: Takaoka et al:: A novel fusogenic herpes simplex virus for oncolytic virotherapy of squamous cell carcinoma. Virology Journal 2011 8:294.

\section{Submit your next manuscript to BioMed Central and take full advantage of:}

- Convenient online submission

- Thorough peer review

- No space constraints or color figure charges

- Immediate publication on acceptance

- Inclusion in PubMed, CAS, Scopus and Google Scholar

- Research which is freely available for redistribution

Submit your manuscript at www.biomedcentral.com/submit
Biomed Central 